\title{
A Pragmatic Study of the Recognition and Interpretation of Verbal Irony by Malaysian ESL Learners
}

\author{
Dr. Sahira M. Salman \\ Development and Research Department \\ Ministry of Higher Education and Scientific Research/Iraq \\ Email: sahirasalman@yahoo.com
}

\section{Doi:10.5901/mjss.2016.v7n2p445}

\begin{abstract}
Verbal irony is understood to be a strategy that uses incongruity between reality and expectation. Since it intends to communicate more than what is literally stated, it is expected that Malaysian ESL learners face difficulty in recognizing and interpreting it. The purpose of this study is to investigate Malaysian ESL learners' competence in recognizing verbal irony and interpreting its functions according to irony type and the strategies used to express them. These are intended to be tested by subjecting Malaysian undergraduate ESL learners to a questionnaire which consists of thirty situations. To investigate the subject's ability in recognizing ironic utterances, both illusional pretense theory by Kumon-Nakamura, et al. (1995) and Utsumi's (2000) implicit display theory are adopted. To investigate the interpretation of ironic utterances, Kreuz and Link (2002) canonical/non-canonical types of irony are identified. These types, in turn, are categorized according to the pragmatic strategies adopted form Gibbs (2000) and the functions associated with them. Also, both descriptive and inferential statistical methods are used to analyse the data. The result of the analysis reveals that, overall, Malaysian ESL learners' performance in recognizing and interpreting verbal irony is very low. It is also concluded that some functions are more easily interpreted in ironic utterances than others and that the strategies used to make verbal irony also affect the extent of its recognition and interpretation. The subjects are able to recognize ironic utterances which are examples of the canonical type more than the non-canonical ones.
\end{abstract}

Keywords: functions, interpretation, pragmatics, recognition, and verbal irony.

\section{Introduction}

"The paradox about ironic communication is that if you want to be understood clearly, you have to be misunderstood." (Anolli, Infantino, \& Cicero, 2002, p. 10)

Irony is a concept which has been studied by philosophers, psychologists, and linguists. As a result, three main principles that explain irony are distinguished: "oppositional (Gricean) irony"(Grice, 1967/1989), "echoic irony"(Sperber \& Wilson, 1981),, and "irony as pretence"(Nakamura, Glucksberg \& Brown, 1995). These three principles have been investigated by linguists as well as psychologists and later developed into new theories. The result of this development is new more logical and accepted approaches to irony description and analysis.

Being a cognitive and linguistic concept, irony forces the reader/hearer to take part in interpreting the intended meaning behind using it since irony does not follow the language norms (Veale, 2013). Although these norms are shared and prevalent, people who use irony are still able to identify exceptional cases which do not follow the standard way of interpretation. Moreover, the recognition and interpretation of ironic utterances requires essential mental abilities (Brown, 1995).

A lot of research has been conducted on the recognition of irony by native speakers. To the researcher's best knowledge, no previous study has been conducted on the pragmatics of recognition and interpretation of verbal irony by Malaysian ESL. This study attempts to provide adequate answers to the following research questions:

1. Overall, to what extent are the Malaysian ESL learners able to recognize cases of verbal irony?

2. Is there any statistically significant difference among students' recognition of verbal irony?

3. Overall, to what extent are the students able to recognize the blaming, praising, humor, evaluative, mocking and persuasive function scores correctly?

4. Are there any statistically significant differences among students' recognition of verbal irony strategies (understatement, Hyperbole, Sarcasm, Rhetorical Question, and Jocularity)?

5. Is there any statistically significant difference among students' recognition of canonical and non-canonical 
irony?

To find answers to these questions, Malaysian undergraduate ESL learners are subjected to a questionnaire which consists of thirty situations. To investigate the subject's recognition of ironic utterances, the "allusional pretense theory" by Kumon-Nakamura et al. (1995) and Utsumi's (2000) "implicit display theory" are adopted.To investigate the interpretation of canonical irony and non-canonical irony, Kreuz \& Link's(2002)model is adopted. These types, in turn, are categorized according to the pragmatic strategies adopted form Gibbs (2000)and the functions associated with them.Moreover, to analyse the data, both descriptive and inferential methods are used.

\title{
2. Review of the Literature
}

\subsection{Definitions and Types of Irony}

Previous literature on irony has shown that the concept of irony is difficult to define. However, there have been so many attempts to define it but it seems that very few are accepted. Littman \& Mey (1991, p. 131) state that "Is it not somewhat ironic [itself] that, for all the effort that linguists, psychologists, authors, and the like have devoted to understanding and using irony, no one can define irony?".In fact, irony is a phenomenon that covers a wide range of functions and connotations that could be negative or positive depending on the intention of the speaker/writer (cf.Anolli et a.l, 2001). Accordingly, many types of irony can be identified but conventionally, there are three main types: situational, dramatic, and verbal irony. The focus of this study is verbal irony, also called "conversational irony" (Lagerwelf, 2007, p. 1705). It is traditionally a figure of speech which refers to the opposite of the literal meaning. Most of the definitions that have been assigned to this type of irony limited verbal irony to the idea of "oppositeness" (cf. Sperber \& Wilson, 1981;Bryant \& Tree, 2002;Attardo, 2001; Wilson, 2006; Simpson, 2011; \&Yetkin, 2011). This problem emerges because those definitions do not explain verbal irony appropriately and there are examples of irony which do not express the opposite meaning. In addition, there are some utterances which carry all the characteristics of verbal irony, but still they are not ironic (cf., Bryant \&Tree, 2002). Besides, verbal irony involves the "difference between the intended and expressed meaning" (Savkaničová, 2013, p. 17). This "difference" is called "incongruity" in Gibbs' (2000)account of verbal irony according to which irony is considered to be a strategy that uses incongruity between reality and expectation. Another more elaborate definition is given by Utsumi (2000) who defines verbal irony as:

\begin{abstract}
a verbal expression (utterance or statement) that implicitly displays an ironic environment. This implicit display of the ironic environment in the most prototypical cases, achieved by an utterance which alludes to the speaker's expectation, violates one of the pragmatic principles, and is accompanied by indirect cues (Utsumi, 2000, p. 1803).
\end{abstract}

The working definition for the purpose of this study is a combination of both Utsumi's(2000, p.1803) and Savkaničová's(2013, p. 17)definitions, for the former gives the meaning of irony and the latter describes the conditions of achieving it. So, according to the present study, verbal irony is defined as a verbal expression (utterance or statement) which involves the difference between the intended meaning and expressed meaning. To achieve this, verbal irony uses incongruity between reality and expectation, oppositeness, and violation of conventions and Grice's Maxims.

Different types of verbal irony can be identified including Socratic and Kind irony (cf. Anolliet al., 2001; Attardo, 2001). Socratic irony is used to blame the addressee through praising him/her literally (i.e. blaming through praising). This type of irony does not aim at making criticism softer. Instead, its aim is to "condemn the interlocutor without emoting him/herself, by humiliating him/her through sarcasm and coldness" (Anolli, et al., 2001, p. 143). While "kind irony" refers to praising the addressee by literally criticising him/her (i.e., praising through blaming). The speaker uses this type of irony so as to "mitigate the excess and euphoria of direct and explicit praise that may sometimes produce embarrassment in the interlocutor" (Anolli, et al., 2001, p.143).

In addition, there has been a great deal of confusion between verbal irony and sarcasm and their relation to humour. Mostly, irony and sarcasm are interchangeably used or considered as belonging to a category that is extensively used and includes humour, fun, laughter, ridicule, etc. whose boundaries are indefinite (Attardo, 2001). Meuke $(1980,54)$ considers sarcasm as "the crudest form of irony. This view is supported by other studies which have argued that both verbal irony and sarcasm belong to irony (cf. Savkaničová, 2013).However, some other studies suggest that sarcasm together with hyperbole, understatement, ambiguity, and jocularity must be regarded as forms of verbal irony (Gibbs, 2000). These types of rhetorical devices can be differentiated by the emotional reactions of listeners in addition to the rhetorical goals of the speakers.

Besides, irony is considered as a form of humorous communication (cf. Attardo, 2001). However, this does not 
entail that humour and irony always co-occur because some ironic utterances are not meant to be funny at all and some humour is not ironic either (Attardo, 2001). On the other hand, Haruki (2000) considers humour as one of the functions of irony in addition to the evaluation function. Consequently, since sarcasm and humour can be found in some ironic utterances, the researchers find it convenient to consider sarcasm as a type of verbal irony and humour as a function used by the speaker to produce verbal irony.

\subsection{Functions of Irony}

Many functions have been assigned to verbal irony. Some of them are social and others are psychological. The psychological functions are concerned with the communicative functions of ironic utterances as being "a sign of respect for conventions", "a border of reserve", and "a relational ambiguity"(Anolliet al., 2001, p. 12). While the social functions of irony include evaluation, aggression, politeness, solidarity, ambiguity, attachment to the members in the society, appearing clever, humor, blaming, ridicule, mocking, making fun, and others(Littmann\& Mey, 1991; Kreuzet al., 1991; Haruki, 200); Clift, 1999; Anolliet al., 2002; Kotthoff , 2003). Consequently, because of the "far-reaching" functions that can be assigned to verbal irony, it is more appropriate to ask "what can't irony do?" than "what can irony do?"(Bryant, 2012, p. 675).Forthe purpose of this study, only six functions selected from a number of sources are employed, depending on the situations selected for the questionnaire. These include: blaming, praising, humor, evaluative, mocking, and persuasive.

\subsection{Irony Interpretation}

Many studies have been conducted on the interpretation and comprehension of irony, some are psycholinguistic and others are linguistic. Giora (2012), for example, studies the psychology of the interpretation of utterances and mentions some factors that affect it like the context, absence or presence of the intended meaning, and shared-knowledge between the participants. In addition, three approaches have been identified in psycholinguistics concerning the interpretation of utterances which have been applied to irony interpretation. These involve models that are based on the context, lexicon, and constrain (cf. Giora, 2012).Moreover, some studies have been applied to irony processing following Grice and Searle's "standard pragmatic model" which is proved to have failed to explain the process of generating meaning in a satisfactory manner. This model is built upon understanding the literal meaning, recognizing its appropriateness in the context, and finally recognizing the appropriate meaning (cf. Kotthoff, 2003). Another study is conducted by Haruki (2000, p. 23) who believes that "irony interpretation is triggered by some kind of inconsistent gap" between two suppositions one is "derived from the propositional content of the utterance" and the other is "entertained in the hearer's mind".

As far as irony comprehension is concerned, psycholinguistic studies propose that the most important thing in irony comprehension is the "degree and nature of the assumptions that the hearer and speaker must share for irony to be understood" (Attardo, 2001, p. 406). However, it is important to notice that irony ought to contain implicit factors that make its interpretation not directly arrived at, especially when the information is not fully provided (Braynt \& Tree, 2002).

\subsection{Approaches to Verbal Irony}

Generally speaking, two approaches to verbal irony can be identified: the traditional approach and the modern approach. The traditional approach considers irony as a figure of speech, i.e. it is a semantic approach to verbal irony. As for the modern approaches, they can be divided into two streams: the pragmatic or rationalistic approach and the psychological or cognitive approach.

\subsubsection{Pragmatic approaches to verbal irony}

Pragmatic approaches to verbal irony include the "oppositional (Gricean)" approach and irony as indirect negation.The oppositional Gricean irony is a pragmatic approach introduced by (Grice, 1967/1989)specifically stressing the idea that irony involves the violation of the maxim of quality. Consequently, irony is a resultant of conversational implicature. Just like the traditional semantic approach, irony, according to Grice, involves the opposite of the literal meaning (cf. Anolli, 2001, Jeong, 2004; Wilson, 2006; andSavkaničová, 2013). It also failed to explain how one moves from the literal to the non-literal meaning (Attardo, 2002; Wilson, 2006). The only distinction between the two approaches, the pragmatic and the traditional, is that the former uses a pragmatic substitution mechanism while the latter uses a semantic one (cf.Attardo, 2002). 
After Grice's approach,Giora (1995) considers irony as a type of indirect negation whose understanding requires processing the negated utterance (the literal meaning) and the implicature (the non-literal meaning). These two theories, i.e. Grice's (1975) and Giora's (1995), presuppose that irony constitutes understanding both the literal and non-literal meaning (Jeong, 2004). However, these approaches are not applicable to all types of verbal irony because there are cases where verbal irony neither involves a violation of Quality Maxim nor negation (Utsami, 2000).

\subsubsection{Psychological Approaches to Verbal Irony}

The other approach to verbal irony is the psychological or cognitive approach. This is considered a post Gricean approach which mainly constitutes three theories, the echoic models, the pretence theory, and the implicit display theory.

\subsubsection{Echoic Models of Verbal Irony}

Many models of the echoic theory have been developed including the echoic use theory (Sperber\& Wilson, 1981), echoic mention (Sperber\& Wilson, 1985), echoic interpretation (Sperber\& Wilson,1995), echoic reminder (Kreuz\&Glucksberg, 1989), and allusionalpretense theory of discourse irony (Kumon-Nakamura et al., 1995). Some of these models, such as the echoic mention and echoic interpretation, describe the linguistic aspects of irony; while the echoic reminder theory describes its pragmatic aspects.

The echoic mention theory, initiated by Sperber\& Wilson (1985), treats verbal irony as a kind of echoic allusion to a recognized utterance or thought. Irony, according to this view, is a "prototypical speech act which does not 'use' the literal meaning to transmit a message, but rather 'mentions' (transmits) it as an 'echo', at the same time expressing a specific attitude toward it" (Kotthoff, 2003, p.1391).

The other model is the allusion pretense theory of discourse irony which is considered as an extension of the previous echoic theories in their linguistic and pragmatic aspects.It is formulated by Kumon-Nakamura, Glucksberg\& Brown (1995).According to this theory, ironic utterances include a violation of norms, predictions, and beliefs. Besides, it is proposed that people believe that life depends on norms that are positive and any utterance which violatesone of these norms will be interpreted as ironic (Gibbs \& Colston, 2007).

\subsubsection{Pretense Theory}

The pretence theory is considered a rival to the echoic theory. It is initiated by Grice (1967/1989). Its aim is to explain why the speakers of ironic utterances do not announce that they will say something ironically, as stated in the following:

To be ironical is, among other things, to pretend (as the etymology suggests), and while one wants the pretence to be recognized as such, to announce it as a pretence would spoil the effect. (Grice, 1967, p. 54)

Later Clark \&Gerrig (1984) adopt this account of irony as a substitute to the echoic theory. They view verbal irony as a kind of pretence according to which the speaker pretends to perform a certain speech act so as to express a certain opinion. Consider the following example from Wilson (2006, p1724).

(1) Mary (after a difficult meeting): That went well.

The speaker of (1) above is not asserting but only pretending to assert that the meeting went well, and is simultaneously expecting the addressee to see through the pretence and recognize the implied critical or sarcastic opinion. In addition, this theory proposed that to interpret verbal irony, the addressee must have the ability to notice that the speaker is pretending and expressing his/her attitude towards the addressee (Wilson, 2006).

Although both the echoic and the pretense theories challenge the traditional and Grice's accounts of irony, they echoic theory is believed to be more applicable to most cases of verbal irony than the pretence theory (Wilson, 2006)

\subsubsection{Implicit Display Theory}

This theory,developed by Utsumi (2000), challenges many of the previous theories of irony. It also distinguishes ironic from non-ironic utterances. According to this theory, two criteria are essential to decide whether a given utterance is ironic. The first one reads that "an utterance must be recognized as achieving implicit display through the process of assessing the degree of ironicalness" (Utsumi, 2000, p.1777). While the second one states that in ironic environment "the discourse situation must be identified as ironic environment through the process of checking or inferring its constituent events/state"(Utsumi, 2000, p.1777). Besides, she views ironic environment in terms of three components according to which the implicit display of those components indicates that an utterance can be accomplished in accordance to the 
following requirements, (a) "alludes to the speaker's expectation E", (b) "includes pragmatic insincerity by intentionally violating one of the pragmatic principles", and (C) "expresses indirectly the speaker's negative attitude toward the failure of E." (Utsumi, 2000, p.1784-1785). Consequently, if an utterance can, at least, directly convey one of the relevant three components of the ironic environment, such an utterance is no longer ironic.

The "implicit display theory" has also given an evidence for the possibility of understanding ironical utterances without ironical cues which goes in line with Gibbs \& O'Brien (1991) who prove that it is possible for people to interpret ironic utterances regardless of any ironic cues like ironic tone of voice, or facial expressions because irony can be interpreted in written discourse as well. This finding is contrary to previous studies such as those of Cutler (1974) and Clark \& Gerrig (1984) who claim that ironic cues can make irony interpretation successful.

\subsection{Previous Studies}

\subsubsection{Kreuz \& Link (2002)}

Kreuz \& Link (2002) identified two types of verbal irony: canonical and no-canonical irony. Canonical irony refers to positive evaluations of negative situation while non- canonical irony refers to negative evaluations of positive situations. Their study has shown that "ironic statements are more typically positive evaluations of negative situations (i.e., canonical irony) than negative evaluations of positive situations (i.e., non-canonical irony)" (Kreuz \& Link, 2002, pp.128-29). They have proved that people respond more to negative utterances than to positive ones because people are more inclined to react to and comment on negative events to save their faces. Kreuz \& Link (2002) conducted three experiments which are designed to assess how irony comprehension by native speakers of English might be affected by the interaction of four variables which include:

whether an expectation is positive or negative, whether the outcome of event is positive or negative, whether the evaluation of the outcome is positive or negative, and the degree of common ground shared by listener and speaker (Kreuz \& Link, 2002, p. 131).

The results of experiments indicate that canonical irony is read more quickly, more ironic, makes more sense, and is more appropriate than non-canonical irony.

\subsubsection{Gibbs (2000)}

In his paper "Irony in Talk among Friends", Gibbs (2000) concentrates on the types, functions, and theories of irony. He has classified the utterances in (62) conversations among native speakers. According to him, irony has different forms which have different communicative functions which, in turn, cause different emotional responses in addressees. In addition, he differentiates between ironic and non-ironic language. After examining the corpus, he finds out that there are five main types of irony including sarcasm ("where speakers spoke positively to reflect a negative intent", jocularity (where speakers teased one another in humorous ways"), hyperbole ("where speakers expressed their nonliteral meaning by exaggerating the reality of the situation"), rhetorical questions ("where speakers literally asked a question that implied either a humorous or critical assertion"), and understatement ("where speakers conveyed their ironic messages by stating far less than was obviously the case") (c.fGibbs, 2012, pp. 11-12). However, these types are also considered as pragmatic cues (c.fBurgers, van Mulken, \& Schellens, 2012).

The result shows that native speakers use many forms of irony when they talk to their friends. Speakers also use jocularity with humor more than sarcasm with an aggressive intention. He has also proved that it is more appropriate to deal with allusional pretense theory by Kumon-Nakamura et al. (1995) which can explain other cases of verbal irony that cannot be explained with echoic mention or pretense.

\section{Methods and Materials}

\subsection{Analytical Framework of Verbal Irony}

To investigate the competence of Malaysian ESL learners in recognizing verbal irony and interpreting its intended functions, an eclectic approach of verbal irony is adapted (see figure (1) below). To investigate student's recognition of ironic utterances, the researcher adopted the allusional pretense theory by Kumon-Nakamura, et al. (1995) which focuses 
on the two requirements of verbal irony: the violation of expectations and norms as well as the inconsistency between the expected situation and the actual one. This theory is adopted because the two requirements are applicable to the examples selected for analysis.Utsumi's (2000) implicit display theory has also been adopted since it specifies the conditions that distinguish ironic utterances from non-ironic utterances. These conditions involve recognizing ironic utterances as achieving an implicit display condition, in addition to identifying the discourse situation as ironic environment.

To investigate the interpretation of ironic utterances, the researcher finds it necessary to adopt Kreuz and Link's (2002) model since it distinguishes between two primary types of irony, i.e., canonical irony and non-canonical irony. These types, in turn, are categorized according to the pragmatic strategies adopted form Gibbs (2000) which include: sarcasm, hyperbole, rhetorical question, jocularity, and understatement. This model is adopted because the situations in the study are examples of these types. The selected functions which are associated with these types are the praising, blaming, humour, evaluative, mocking, and persuasive selected from sources employed in this study.

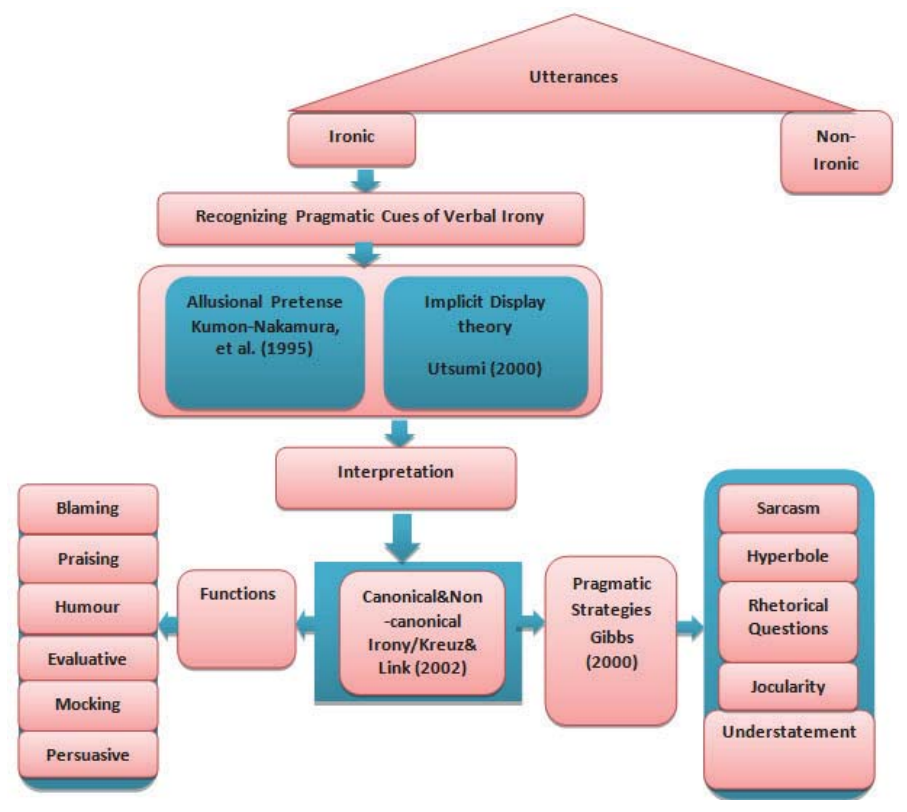

Figure (1): Analytical Framework of Verbal Irony

\subsection{Data Collection}

The data of the study have been collected by means of a questionnaire submitted to Malaysian undergraduate ESL learners at Department of English/ Faculty of Modern Languages and Communication/ University of Putra Malaysia UPM, a group of five native English speakers working at ELS in Malaysia.

\subsubsection{The Questionnaire}

This study employs the "textoid" procedure proposed by Graesser et al. (1977). According to this procedure, the participants in the questionnaire are asked to read a series of short scenarios that constitute two or more characters who interact with each other, and end with one of the characters making a comment to the other characters. The questionnaire includes 30 situations, each of which represented a real-life communicative situation which is likely to occur in the target language community. It is built upon various situations selected from a number of sources consulted in this study. Some situations, however, have been modified a little by the researcher to ensure the subjects' understanding of the situations, the appropriateness of which has been approved by the control group of the native speakers with some modifications that have been taken into consideration in designing the final version of the questionnaire. 
Each situation consists of four options, three of them are non-ironic and only one is intended to be an example of verbal irony with a certain function. In addition, participants are asked to select the function of the selected ironic utterance. Moreover, each ironic utterance is intended to be expressed through a strategy chosen from a list of strategies adopted in this study. The answers of the native speakers who represent the control group of the study are taken as the key responses against which Malaysian subjects' answers are measured. The subjects are required to encircle the ironic utterance and then encircle its intended function.

\subsubsection{Subjects}

The sample of the study consists of two groups: the first group involves 84 Malaysian undergraduate ESL learners, aged 20-25 randomly chosen from the Department of English/ Faculty of Modern Languages and Communication/ University of Putra Malaysia during the academic year 2014-2015. All the participants were ESL learners. The second group includes five American English native speakers working at ELS in Malaysia.

\subsubsection{Task Administration}

The aim behind the questionnaire was explained to the Malaysian ESL learners in addition to the instructions to the way of responding to it. Besides, students were encouraged to ask for any illustration regarding how to respond to the questionnaire.

Content validity of the questionnaire was measured by constructing it in a way that measured only what was required by it. Additionally, the questionnaire was given for assessment to five native speakers who have approved it.

\section{Results and Findings}

This section presents the results and findings of the study. Both descriptive and inferential methods were used to analyse the data. Descriptive results, including frequency and percentage values have been reported in brackets as ( $F, P \%)$ while means and standard deviations have been reported in brackets as $(M, S D)$.

Research question 1: Overall, to what extent are the students able to recognize cases of irony?

To answer this research question, all the students' irony recognition total scores were calculated. Each correct response was given one point, resulting in a cumulative total score of (30). The three irony recognition categories of students were created by dividing the total score (30) into three equal intervals; thus, scores ranging between 0 and 10 were considered 'low', (11-20) were regarded as 'moderate' and (21-30) were categorized as 'high'. Based on the results (Table 1), a majority of the students $(44,51.8 \%)$ indicated low irony recognition skills. A very small proportion of the students $(11,12.9 \%)$ could score (21) to (30) items accurately and thus were classified as having a high ability in recognizing irony. These results suggest that, overall, the students would find it difficult to recognize ironic utterances in English due to the fact that ironic utterances are cases for expressing the intended meaning implicitly. The majority of the subjects even consider some non-ironic utterances as ironic though the context provides information which implies that they are not. As in the situation below from Utsumi $(2000,1796)$ :

Situation: Against Judy's advice, Bill bought what a crooked art dealer told him was a true Picasso. Roger, claiming to be competent, vouched for the painting's authenticity. Other friends of Bill's were much impressed by the painting until a genuine expert at last showed it to be a fake. Judy then says to them:

a. That was a truly beautiful Picasso.

b. Picasso is not easily found or bought.

c. You should have listened to my advice.

d. You proved to be so incompetent.

In the abovesituation, very few students successfully recognized (a) as an example of verbal irony. In this utterance, what the speaker intends is the opposite, not the literal meaning. It means that Judy's real opinion is that the painting is fake. The utterance involves a violation of Grice's quality maxim. It also implicitly displays the ironic situation and the speaker is pretending that the painting is true. As for items (b), (c), and (d), they just express the speaker's opinion explicitly, however, many subjects recognized them as ironic. 
Table 1: Irony recognition categories

\begin{tabular}{lcc}
\hline & Frequency & Percent \\
\hline Low & 44 & 51.8 \\
Moderate & 30 & 35.3 \\
High & 11 & 12.9 \\
\hline Total & 85 & 100.0 \\
\hline
\end{tabular}

Research question 2: Is there any statistically significant difference among the students' recognition of verbal irony?

A test value of (15) was defined as the cut-off point which differentiated low from high level students in reference to their ability to recognize cases of irony accurately. Descriptive statistics results $(M=11.5, S D=6.4)$ indicated that the students scored below average. Furthermore, based on the one-sample t-test results (Table 2), t(84) $=-5.018, p<.05$, this difference was statistically significant. It was concluded that the students' ability to recognize cases of irony was significantly below the standard level. Consider the following situation from Haruki (2000, p. 20):

-Situation: Joan is driving. Trying to make a left turn, she does not signal and gets into a potentially dangerous situation.

Sally, on the passenger seat, comments:

a. I hate people who don't signal.

b. Not paying attention causes accidents

c. Don't you think signalling is important?

d. I love people who signal.

Only (d) in the above example is an expression of verbal irony because it implicitly shows that she dislikes this behaviour and consequently dislikes people who do not signal. As for (a), (b), and (c), they all express Sally's explicit dislike to the situation, and therefore non-ironic. However, many students preferred to choose (a), (b), or (c) to be ironic. This indicates that the subjects do not prefer pretence in expressing their opinion in communicating with others and would rather rely on directness.

Table 2: One-Sample Statistics $(n=85$, Test Value $=15)$

\begin{tabular}{cccccccc}
\hline \multirow{2}{*}{ Mean } & \multirow{2}{*}{ Std. Deviation } & T & Df & Sig. (2-tailed) & \multirow{2}{*}{ Mean Difference } & \multicolumn{2}{c}{ 95\% Confidence Interval of the Difference } \\
\cline { 6 - 7 } & & & & & & Lower & Upper \\
\hline 11.5059 & 6.41914 & -5.018 & 84 & .000 & -3.49412 & -4.8787 & -2.1095 \\
\hline
\end{tabular}

Research question 3: Overall, to what extent are the students able to recognize the blaming, praising, humor, evaluative, mocking and persuasive function scores correctly?

Before analysing the data, five cases were filtered since they failed to answer the items eliciting information on their ability to recognize different types of functions; therefore, their data were all missing. Based on the descriptive statistics results, praising, persuasive, and blaming functions achieved the three highest mean scores $(M=25.41,24.38$, and 23.65; SD = 2.89, 3.3, and 2.96), respectively (Table 3). These high mean scores showed that subjects found it easier to assign the praising, persuasive, and blaming functions to ironic utterances. Moreover, these functions seemed to be more easily interpreted than the evaluative, humor, and mocking functions whose mean scores were $(M=19.51,17.47$, and 15.85) respectively. These very low mean scores indicated that these functions were not easily interpreted in ironic utterances. They also mean that the subjects rarely use mocking and humor in ironic utterances. They prefer to use irony for praising, persuading and blaming but not for making fun or teasing the addressee. Accordingly, the subjects interpreted irony as generally having positive rather than negative implications. However, the results show that it was not easy for the subject to assign the right function to the ironic utterances due to the fact that there are many functions that ironic utterances could have.

Although, some studies suggest that humor makes it easier to detect ironic utterances, this study finds out that the Malaysian ESL learners do not easily recognize verbal irony which has the humour function since the students mean score (MS= 17.47). Consider the following situation from Haruki $(2000$, p. 20):

Situation: Sam and Arnold are scholars who work for the same university. Sam knows that Arnold thinks that Sam's Laboratory is tidy. Arnold said:

a. What a messy lab! 

b. What an organized Lab!
c. Your lab needs more tools.
d. It seems that you don't like messy places.

Many students considered (a) above which is an example of verbal irony that carried the humour function as expressing the mocking function. The context clearly showed that Arnold did not mean what he had said literally, as long as he knew that Sam's laboratory was tidy; however, the subjects did not recognize the humor in the utterance. Arnold aimed to be humorous and not to mock at Sam. Consequently, the ability of the subjects of the study to interpret the humor function of verbal irony is very weak.

Table 3. Descriptive statistics results for function scores $(n=80)$

\begin{tabular}{lcc}
\hline Function scores & Mean & Std. Deviation \\
\hline Blaming & 23.6500 & 2.96861 \\
Praising & 25.4125 & 2.89781 \\
Humor & 17.4750 & 3.86472 \\
Evaluative & 19.5125 & 4.54790 \\
Mocking & 15.8500 & 3.97810 \\
Persuasive & 24.3875 & 3.30896 \\
\hline
\end{tabular}

The largest difference was recorded between praising function $(M=25.4, S D=2.8)$ and mocking function $(M=15.8, S D$ $=3.9$ ) scores which supported what was previously mentioned that the subjects use irony with positive intentions rather than negative intentions.

The largest difference was recorded between praising function $(M=25.4, S D=2.8)$ and mocking function $(M=$ $15.8, S D=3.9)$ scores. Furthermore, repeated measures ANOVA results indicated an overall significant difference, $F(1$, $79)=4886.2, p<.001$, among the six categories of function scores (Table 4).

Table 4: Repeated measures results between-Subjects Effects of function scores $(n=80)$

\begin{tabular}{lcccccc}
\hline Source & Type III Sum of Squares & Df & Mean Square & F & Sig. & Partial Eta Squared \\
\hline Intercept & 212647.102 & 1 & 212647.102 & 4886.215 & .000 & .984 \\
Error & 3438.065 & 79 & 43.520 & & & \\
\hline
\end{tabular}

Research question 4:Are there any statistically significant differences among students' recognition of verbal irony strategies (understatement, Hyperbole, Sarcasm, Rhetorical Question, and Jocularity)?

Table 5 shows the descriptive statistics results:

Table 5. Descriptive Statistics for students' recognition scores of verbal irony according to the five strategies of irony

\begin{tabular}{lccc}
\hline Categories & Mean & Std. Deviation & $\mathrm{N}$ \\
\hline Understatement & 22.3529 & 24.33683 & 85 \\
Hyperbole & 45.2941 & 22.94630 & 85 \\
Sarcasm & 31.7647 & 24.49687 & 85 \\
Rhetorical Question & 36.0784 & 25.82592 & 85 \\
Jocularity & 42.2059 & 26.09054 & 85 \\
\hline
\end{tabular}

Based on these results, hyperbole had the highest mean scores, whereas understatement received the lowest $(M=$ $45.29, S D=22.94 ; M=22.35, S D=24.33$ ). It can be concluded that the strategies of irony recognition which the students found the easiest to the most difficult were hyperbole, jocularity, rhetorical question, sarcasm, and understatement. In order to answer the research question, repeated measures ANOVA was run. This showed an overall significant difference, $F(3.57,300.32)=26.61, p<.001$, among the students' scores for the five strategy scores. As shown in table (5) above, hyperbole and jocularity have the highest mean scores $(M=45.29,42.20)$ respectively. The results showed that exaggeration, expressed through hyperbole, and teasing, expressed through jocularity were effective strategies that madethe recognition of verbal irony easier. Consider the following situation from Reyes, Rosso, \& Veale (2013, p.241): 
Situation: A professor explains and re-explains Hegel's theory of the State to his class of undergraduates, he asks, "Is it clear now". A student replies:

a. Clear as mud.

b. Not very much.

c. It is not easy.

d. We need more explanations. I think.

The jocularity of (a) in the above situation was expressed through violating the convention that mud cannot be clear. While the other three options just express the student's opinion directly. This proved that jocularity was an effective strategy for recognizing and interpreting verbal irony as shown in the significant mean score $(M=42.20)$.

The lowest mean score was shown in the understatement strategy $(M=22.35)$ which indicated that the subjects of the study did not recognize utterances which stated less than what was required as being ironic.

Research question 5: Is there any statistically significant difference among students' recognition of canonical and non-canonical irony?

Compared with that of the non-canonical irony $(M=21.17, S D=22.91)$, canonical irony obtained a higher mean score $(M=42.25, S D=22.38)$. The results of the paired samples t-test indicated a statistically significant difference $[t(84)$ $=11.39, p<.001$ ] between these means scores (seeTables6-7 below). The result showed that in comparing the canonical and non-canonical irony, canonical irony played an important role in irony recognition. Malaysian ESL learners were able to recognize utterances which were examples of the canonical type more than the non-canonical ones. Consider the following situation from Attardo (2001):

Situation: Mrs. Moor is the 80-year-old grandmother of Jane, a 30-year-old female. Jane had just run up over a curb driving out of a store. Mrs. Moor said to Jane:

1. You are a careless driver.

2. They just built that while you were in the store.

3. You should be careful next time.

4. I am afraid next time you run up over a person.

Moor's grandmother was blaming her for not paying attention while driving and expressed this by giving an excuse for this accident. In fact, she was implicitly her since the idea that the store was built while she was in the store was completely not true. Such type of irony was recognized more easily than the non-canonical irony, as in the following situation from Anolli et al. (2001):

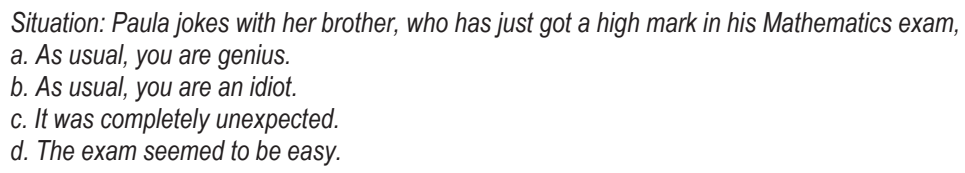

Although Sam, in the above situation, got a high mark in the exam, his sister, instead of praising him directly, she dispraised him and considered this a sign of idiocy. Many of the subjects were not able to recognize the irony in (b) and preferred to choose the direct praising instead. This gave evidence that the main aim behind using verbal irony is to blame more than to praise. The result goes in line with the findings of Kreuz and Link's (2002) previous study on native speakers of English concerning canonical and non-canonical irony.

Table 6. Paired Samples Statistics $(n=85)$

\begin{tabular}{lccc}
\hline Irony & Mean & Std. Deviation & Std. Error Mean \\
\hline Canonical Irony & 42.2549 & 22.38426 & 2.42791 \\
Non-Canonical Irony & 21.1765 & 22.91407 & 2.48538 \\
\hline
\end{tabular}

Table 7. Paired Samples Test $(n=85)$

\begin{tabular}{|c|c|c|c|c|c|}
\hline \multirow{3}{*}{ Mean } & \multirow{3}{*}{ Std. Deviation } & \multicolumn{2}{|c|}{ Paired Differences } & \multirow{3}{*}{\multicolumn{2}{|c|}{ df Sig. (2-tailed) }} \\
\hline & & \multirow{2}{*}{ Std. Error Mean } & $95 \%$ Confidence Interval of the Difference & & \\
\hline & & & $\begin{array}{ll}\text { Lower } & \text { Upper } \\
\end{array}$ & & \\
\hline 21.07843 & 17.05104 & 1.84944 & 24.75625 & 11.39784 & .000 \\
\hline
\end{tabular}




\section{Conclusions}

This study reveals that, overall, Malaysian ESL learners face difficulty in recognizing ironic from non-ironic utterances. Their ability to recognize cases of irony is significantly below the standard level. Since ironic utterances are cases of expressing the intended meaning implicitly, the subjects are not inclined to pretend when expressing their opinion in communicating with others and would rather rely on directness. This is proved by the high rate of the non-ironic utterances in which the opinion is expressed directly.

The results have also shown that the subjects find it easier to assign the praising, persuasive, and blaming functions toironic utterances. While assigning the evaluative, humor, and mocking functions to ironic utterances is very low which indicates that Malaysian ESL learners find these functions difficult to be interpreted in ironic utterances. They also designate that the subjects rarely use mocking and humor in expressing verbal irony. They prefer to use irony for praising, persuading and blaming not for making fun or teasing the addressee. Accordingly, irony is interpreted, according to the subjects of the study, as generally having positive rather than negative implications. However, the results show that it is not easy to assign the right function to the ironic utterances due to the fact that there are many functions that ironic utterances could have. Besides Malaysian ESL learners do not easily recognize verbal irony which carries the humour function. This result could imply that the subjects are not very much humorous by nature and this affects the interpretation of the ironic utterances functions.

The analysis of the data also gives evidence that the strategies of irony recognition which the students find the easiest to the most difficult are hyperbole, jocularity, rhetorical question, sarcasm, and understatement. This proves that hyperbole and jocularity are effective strategies that make irony recognition and interpretation easier, while understatement is regarded as the most difficult strategy that makes irony recognition very difficult. The result indicates that the subjects of the study are not able to recognize utterances which state less than what is required as being ironic.

The results of the study have also shown that, in comparing the canonical and non-canonical irony, canonical irony plays an important role in irony recognition. Malaysian ESL learners are able to recognize ironic utterances which are examples of the canonical type more than the non-canonical ones. This result gives evidence that the main aim behind using verbal irony is to attack or blame rather than to praise.

\section{References}

Anolli, L., Infantino, M. G., \& Ciceri, R. (2002). " You're a Real Genius!": Irony as a Miscommunication Design. Emerging communication, 3, 135-158.

Attardo, S. (2001). Humor and Irony in Interaction: From Mode Adoption to Failure of Detection in Anolli, L., Ciceri, R., Riva, G. New Perspectives in Miscommunication, IOS Press.

Attardo, S. (2002). Humor and irony in interaction: From mode adoption to failure of detection. EMERGING COMMUNICATION, 3, 159180.

Brown, P. (1995). Politeness strategies and the attribution of intentions: the case of Tzeltal irony. Social Intelligence and Interaction, Cambridge University Press, Cambridge, 153-174.

Bryant, G. A. (2012). Is Verbal Irony Special? Language and Linguistics Compass, 6(11), 673-685.

Bryant, G. A., \& Fox Tree, J. E. (2002). Recognizing verbal irony in spontaneous speech. Metaphor and symbol, 17(2), 99-119.

Burgers, C., van Mulken, M., \& Schellens, P. J. (2012). Type of evaluation and marking of irony: The role of perceived complexity and comprehension. Journal of Pragmatics, 44(3), 231-242.

Clark, H. H., \& Gerrig, R. J. (1984). On the pretense theory of irony.

Clift, R. (1999). Irony in conversation. Language in society, 28(04), 523-553.

Cutler, A. (1974). On saying what you mean without meaning what you say. MW LaGaly, RA, Fox, and A., Bruck [Eds], Chicago Linguistic Society, Chicago, 117-127.

Gibbs, R. W. (1994). The poetics of mind: Figurative thought, language, and understanding: Cambridge University Press.

Gibbs, R. W. (2000). Irony in talk among friends. Metaphor and symbol, 15(1-2), 5-27.

Gibbs, R. W. (2012). Are ironic acts deliberate? Journal of Pragmatics, 44(1), 104-115.

Gibbs, R. W., \& Colston, H. L. (2007). Irony in language and thought: A cognitive science reader. Psychology Press.

Giora, R. (1995). On irony and negation. Discourse processes, 19(2), 239-264.

Giora, R. (2012). The psychology of utterance processing: Context vs salience. The Cambridge Handbook of Pragmatics, 151-167.

Grice, H. P. (1967). Logic and conversation: The William James lectures. In (reprinted in Studies in the way of words): Cambridge, MA: Harvard University Press.

Grice, H. P. (1989). Indicative conditionals. Studies in the Way of Words, Harvard University Press, Cambridge, MA, 58-85.

Haruki, S. (2000). Jocularity in irony and humor: A cognitive-to-affective process.

Jeong, J. (2004). Verbal Irony and Situational Irony: Why do people use verbal irony?

Kotthoff, H. (2003). Responding to irony in different contexts: On cognition in conversation. Journal of Pragmatics, 35(9), $1387-1411$. 
Kreuz, R. J., \& Glucksberg, S. (1989). How to be sarcastic: The echoic reminder theory of verbal irony. Journal of Experimental Psychology: General, 118(4), 374.

Kreuz, R. J., \& Link, K. E. (2002). Asymmetries in the use of verbal irony. Journal of Language and Social Psychology, 21(2), 127-143.

Kreuz, R. J., Long, D. L., \& Church, M. B. (1991). On being ironic: Pragmatic and mnemonic implications. Metaphor and symbol, 6(3), $149-162$.

Kumon-Nakamura, S., Glucksberg, S., \& Brown, M. (1995). How about another piece of pie: The allusional pretense theory of discourse irony. Journal of Experimental Psychology: General, 124(1), 3.

Lagerwerf, L. (2007). Irony and sarcasm in advertisements: Effects of relevant inappropriateness. Journal of Pragmatics, 39(10), 17021721.

Littman, D. C., \& Mey, J. L. (1991). The nature of irony: Toward a computational model of irony. Journal of Pragmatics, 15(2), 131-151.

Muecke, D. (1980). The Compass of Irony. 1969. New York: Methuen.

Savkaničová, M. (2013). Pragmatic Analysis of Ironic Humour in Black Books.

Simpson, P. (2011). That's not ironic, that's just stupid: Towards an eclectic account of the discourse of irony'. The Pragmatics of Humour across Discourse Domains. Pragmatics and Beyond New Series. Amsterdam/Philadelphia: John Benjamins, 33-50.

Sperber, D., \& Wilson, D. (1981). Irony and the use-mention distinction. Philosophy, 3, 143-184.

Sperber, D., \& Wilson, D. (1985). Loose talk. Paper presented at the Proceedings of the Aristotelian Society.

Sperber, D., \& Wilson, D. (1995). Postface. Sperber, D. and Wilson D. 1995a, 255-279.

Utsumi, A. (2000). Verbal irony as implicit display of ironic environment: Distinguishing ironic utterances from nonirony. Journal of Pragmatics, 32(12), 1777-1806.

Veale, T. (2013). Humorous similes. Humor, 26(1), 3-22.

Wilson, D. (2006). The pragmatics of verbal irony: Echo or pretence? Lingua, 116(10), 1722-1743.

Yetkin, N. (2011). A Case Study on the Humorous Load Differences and Cognitive Effects of Satirecally/lronically Humorous Elements in Subtitling from English into Turkish. The Journal of Linguistic and Intercultural Education, 4, 239. 